\title{
Performance Evaluation of Maize Hybrids (Zea mays L.)
}

\author{
B. Manjunatha*, B. Niranjana Kumara and G.B. Jagadeesh \\ Agricultural and Horticultural Research Station, Kathalagere, University of Agricultural and \\ Horticultural Sciences, Shivamogga, Karnataka, India \\ *Corresponding author
}

\begin{abstract}
A B S T R A C T
\end{abstract}
\section{Keywords}

Heritability, Hybrids,

Genetic advance,

Correlation, PCV, GCV

Article Info

Accepted:

10 October 2018

Available Online:

10 November 2018
The study was conducted to evaluate the performance of 100 maize hybrids and to assess the association between yield and yield component traits of maize hybrids. The Experiment was carried out in randomized complete block designs (RCBD) with three replications in 2017 main cropping season. The analysis of variance revealed significant differences between hybrids for all measured parameters. The highest and lowest grain yield were recorded for VH132059 (11.11ton/ha) and VH141651 (6.06 ton/ha) respectively. Among the Hybrids VH15471 and VH15884 were early maturing varieties, while VH11153 and VH112944 are late maturing hybrids. Higher phenotypic coefficient of variation $(\mathrm{PCV})$ and Genotypic coefficient of variation (GCV) were recorded for the traits plant aspect, ear aspect, number of cobs per plant and grain yield. High heritability and high genetic advance were recorded for plant height, number of grain per row and cob length VH132059 and VH11128 are good performed hybrids.

\section{Introduction}

Maize (Zea mays L.) is the third most important cereal crop after wheat and rice. Improving maize production is considered to be one of the most important strategies for food security in the developing countries (Iqbal et al., 2001). Maize grain today is recognized worldwide as a strategic food and feed crop that provides an enormous amount of protein and energy for humans and livestock (FAOSTAT, 2008).

Maize production in the area suffers much from low fertility, low management, lack of improved varieties, and very severe infections of foliar diseases like turcicum leaf blight, high infestations of striga and stalk borers (Assefa, 1998). As a result, evaluating the performance of hybrid maize genotypes in specific agro ecology on different traits is very crucial. Maize improvement in India started an century ago and several promising hybrids and composite varieties were introduced and evaluated at different locations (Benti et al., 1997).

However, the changing environmental conditions affect the performance of maize genotypes which requires a breeding program that needs to take into account the consequences of environment and genotype interaction in the selection and release of improved varieties. Hence, the overall 
objectives of this study were to evaluate the performance of the tested hybrid maize and to identify superior maize germplasms for better productivity to maize growers.

\section{Materials and Methods}

The experiment was laid out in a randomized complete block design (RCBD) with three replications composed of 100 hybrids (Table 1) conducted under rain fed condition during 2016 in kharif season at Agricultural and Horticultural Research Station, Kathalagere, Davangere district under University of Agricultural and Horticultural Sciences, Shivamogga, Karnataka.

Each plot comprised of $5.1 \mathrm{~m}$ long with the spacing of $0.60 \mathrm{~m}$ between rows and $0.30 \mathrm{~m}$ between plants. Two seeds were planted per hill and later thinned out to one healthy plant. The recommended fertilizer dose (urea@150 $\mathrm{kg} / \mathrm{ha}$ and DAP@150 kg/ha) was used. DAP fertilizer was applied once at planting while urea was applied twice equally at planting and at knee height stage of the crop. All other management practices were uniformly applied to all experimental plots as per package of practice.

Data were recorded on plot and plant basis for the following characteristics; days to $50 \%$ anthesis, days to $50 \%$ silk emergence, days to maturity, grain yield, plant height, ear height and number of cobs/plant.

Analysis of variance (ANOVA) was done by using INDOSTAT software. The phenotypic and genotypic coefficients of variation were estimated according to the method suggested by Burton and De Vane (1953).

Broad sense heritability (h2) expressed as the percentage of the ratio of the genotypic variance to the phenotypic variance as described by Allard (1960).

\section{Results and Discussion}

\section{Analysis of variance}

The results of analysis of variance (ANOVA) of the quantitative traits of the tested genotypes are presented in (Table 2). The analysis of variance result showed that there were considerable amount of variation between the tested hybrids. Results showed highly significant variation $(\mathrm{p}<0.01)$ for days to $50 \%$ anthesis, days to $50 \%$ silking, days to $50 \%$ maturity, plant height, plant aspect, cob weight, cob length and number of grains per row and significant variation $(\mathrm{p}<0.05)$ for ear height, ear aspect, number of cobs per plant, grain yield. This result is in agreement with the findings of Soza et al., (1996); Sallah et al., (2001); Ram Reddy et al., (2013). Maximum grain yield (11.11 ton/ha) was observed for VH132059 whereas the minimum grain yield (6.06 ton/ha) was recorded for VH141651 (Table 2).

\section{Phenotypic and genotypic variation}

The phenotypic variance was separated into genotypic and environmental variances to estimate the contribution of each to the total variation. The minimum (0.2) and maximum (50.9) percentages of phenotypic coefficient of variation (PCV) were observed for plant height and number of diseased cobs, respectively.

The PCV values for number of diseased cobs and ear height were high. It indicates on these traits the phenotypic difference between the tasted genotypes is high. PCV values for number of cobs per plant, cob weight and number of grains per row, stand count at harvest and cob length were medium. It indicates the phenotypic difference between the tested maize genotypes with the above traits is moderate (Bello et al., 2012; Golam et al., 2014). Days to maturing, plant height, 
days to anthesis, days to silking and grain yield had low PCV values (Ram Reddy et al., 2012). Low PCV observed for days to maturing, plant height, days to anthesis and days to silking Genotypic coefficient of variation measures the genetic variability with in a character. The extent of the environmental influence on any character is indicated by the magnitude of the differences between the genotypic and phenotypic coefficients of variation. Large differences reflect high environmental influence, while small differences reveal that the influence of environment on the genetic variance is low (Manjunatha et al., 2018). The small difference between PCV and GCV of these traits indicated the possibility of genetic improvement of the traits. Genotypic coefficients of variability (GCV) values were low for days to maturing, days to anthesis and days to silking. Medium GCV was observed for plant height, ear height, number of cobs per plant, number of grain per row, cob weight (Golam et al., 2014).

Higher PCV and GCV were recorded for the traits number of cobs per plant, grain yield and number of diseased cobs. It shows that the selection can be effective for these traits and also indicated the existence of substantial variability, ensuring ample scope for their improvement through selection. From this result by selecting the genotype with higher number of cobs per plant, better grain yield and less number of diseased cobs can improve the grain yield of maize.

The difference between PCV with the corresponding GCV values was relatively higher for plant height, ear aspect andgrain yield, indicating the higher influence of the environment on the traits. However, this difference was comparatively low for days to anthesis, days to silking, days to maturing, number of grain per row, stand count at harvest and cob length. The small difference indicating that there is a minimal influence of environment on the expression of these traits. In addition, it indicates the presence of sufficient genetic variability for observed traits may facilitate the selection process. Therefore, selection based on phenotypic performance of the traits would be effective to bring considerable improvement in these traits.

\section{Heritability and genetic advance}

Heritability is the proportion of genetic variance and phenotypic variance. It is a major parameter for the selection of superior population improvement method. Knowledge about heritability of quantitative traits of a crop plant is of extreme interest to plant breeders. The heritability estimates detected for the characters studied ranged between $39.7 \%$ for number of cobs per plant to $98.9 \%$ for date of anthesis. High levels of heritability were estimated for days to anthesis, days to silking, days to maturing, plant height, number of grains per row, stand count at harvest and cob length (Beyene, 2005); Muhammad (2009) for days to anthesis and number of grains per row Sarlangue et al., (2007).

High heritability of the above traits indicated that influence of environment on these characters is negligible or low. Therefore, selection can be effective on the basis of phenotypic expression of these traits in the individual plant by implementing simple selection methods. Medium heritability was recorded for ear height, number of cob per plant, cob weight, grain yield. The moderate levels of heritability indicated that this trait was moderately influenced by environmental factors (Lorenzana and Bernardo, 2008). Genetic advance under selection (GA) refers to the improvement of traits in genotypic value for the new population compared with the base population less than one cycle of population at a given intensity (Singh, 2001). 
Table.1 List of hybrids

\begin{tabular}{|c|c|c|c|c|c|}
\hline 1 & VH131306 & VH131306 & 51 & VH112744 & VH112744 \\
\hline 2 & VH133273 & VH133273 & 52 & VH141640 & VH141640 \\
\hline 3 & VH141552 & VH141552 & 53 & VH121082 & VH121082 \\
\hline 4 & VH125 & VH125 & 54 & VH11128 & VH11128 \\
\hline 5 & VH11431 & VH11431 & 55 & ZH112035 & ZH112035 \\
\hline 6 & VH11301 & VH11301 & 56 & VH123389 & VH123389 \\
\hline 7 & VH11441 & VH11441 & 57 & VH141651 & VH141651 \\
\hline 8 & VH113012 & VH113012 & 58 & VH123061 & VH123061 \\
\hline 9 & VH13296 & VH13296 & 59 & VH12328 & VH12328 \\
\hline 10 & VH13305 & VH13305 & 60 & VH13554 & VH13554 \\
\hline 11 & VH13306 & VH13306 & 61 & VH141682 & VH141682 \\
\hline 12 & VH13700 & VH13700 & 62 & VH15911 & VH15911 \\
\hline 13 & VH13729 & VH13729 & 63 & ZH115995 & ZH115995 \\
\hline 14 & VH13740 & VH13740 & 64 & КН141554 & KH141554 \\
\hline 15 & VH112888 & VH112888 & 65 & VH16161 & VH16161 \\
\hline 16 & VH11131 & VH11131 & 66 & VH122850 & VH122850 \\
\hline 17 & VH11153 & VH11153 & 67 & VH131199 & VH131199 \\
\hline 18 & VH112944 & VH112944 & 68 & VH123031 & VH123031 \\
\hline 19 & VH11134 & VH11134 & 69 & VH11812 & VH11812 \\
\hline 20 & VH13917 & VH13917 & 70 & VH131376 & VH131376 \\
\hline 21 & VH1640 & VH1640 & 71 & VH133765 & VH133765 \\
\hline 22 & VH132079 & VH132079 & 72 & VH153409 & NK30 \\
\hline 23 & VH132059 & VH132059 & 73 & VH153410 & Swarna \\
\hline 24 & VH151139 & VH151139 & 74 & VH153411 & Mukta \\
\hline 25 & VH132169 & VH132169 & 75 & VP15297 & African tall \\
\hline 26 & VH16100 & VH16100 & 76 & TA5024 & TA5024 \\
\hline 27 & VH123015 & VH123015 & 77 & TA5104 & TA5104 \\
\hline 28 & VH1230 & VH1230 & 78 & TA5114 & TA5114 \\
\hline 29 & VH161055 & VH161055 & 79 & TA5144 & TA5144 \\
\hline 30 & VH15471 & VH15471 & 80 & TA5084 & TA5084 \\
\hline 31 & VH15496 & VH15496 & 81 & VH112651 & NK6240 \\
\hline 32 & VH132461 & VH132461 & 82 & VH112649 & 900MGold \\
\hline 33 & VH1652 & VH1652 & 83 & VH131025 & DKC8101 \\
\hline 34 & VH15884 & VH15884 & 84 & VH112667 & $30 \mathrm{~V} 92$ \\
\hline 35 & VH1660 & VH1660 & 85 & VH153412 & D2244 \\
\hline 36 & VH15537 & VH15537 & 86 & VH112655 & HTMH5101 \\
\hline 37 & VH141618 & VH141618 & 87 & VH131019 & P3396 \\
\hline 38 & VH112972 & VH112972 & 88 & $31 Y 45$ & $31 \mathrm{Y} 45$ \\
\hline 39 & VH11150 & VH11150 & 89 & VH151758 & Pratap QPM Hybrid-1 \\
\hline 40 & VH11138 & VH11138 & 90 & AH1223 & 9108 \\
\hline 41 & VH1253 & VH1253 & 91 & DHM121 & DHM121 \\
\hline 42 & VH12264 & VH12264 & 92 & WIN Orange & WIN Orange \\
\hline 43 & VH11130 & VH11130 & 93 & Hema & Hema \\
\hline 44 & VH112906 & VH112906 & 94 & VH171212 & Ravi-81 \\
\hline 45 & VH113027 & VH113027 & 95 & VP1760 & Pant Sankar Makka-3 \\
\hline 46 & VH12241 & VH12241 & 96 & VH171213 & P3502 \\
\hline 47 & VH151280 & VH151280 & 97 & VH171214 & HTMH5106 \\
\hline 48 & VH131026 & VH131026 & 98 & VH171215 & DKC9144 \\
\hline 49 & VH141229 & VH141229 & 99 & VH171254 & Shaktiman-4 \\
\hline 50 & VH112740 & VH112740 & 100 & VH151757 & Shaktiman-5 \\
\hline
\end{tabular}


Table.2 Estimates of range, mean and genetic parameters on the tested maize hybrids

\begin{tabular}{|l|c|c|c|c|c|c|c|c|} 
& $\begin{array}{c}\text { Grain } \\
\text { yield }\end{array}$ & $\begin{array}{c}\text { Days to } \\
\text { Anthesis }\end{array}$ & $\begin{array}{c}\text { Days to } \\
\text { Silking }\end{array}$ & $\begin{array}{c}\text { Plant } \\
\text { height }\end{array}$ & $\begin{array}{c}\text { Ear } \\
\text { height }\end{array}$ & $\begin{array}{c}\text { Ear } \\
\text { position }\end{array}$ & $\begin{array}{c}\text { Lodging } \\
\text { root }\end{array}$ & Cobs/plant \\
\hline Mean & 8.17 & 51.3 & 54.9 & 260.8 & 107.4 & 0.42 & 2.9 & 1.10 \\
\hline Min & 3.74 & 45.1 & 49.4 & 196.6 & 77.3 & 0.32 & -1.4 & 0.65 \\
\hline Max & 12.14 & 56.7 & 59.7 & 294.2 & 136.6 & 0.52 & 70.8 & 1.63 \\
\hline Lower Limit & 0.00 & 50.0 & 50.0 & 30.0 & 30.0 & 0.10 & 0.0 & 0.00 \\
\hline Upper Limit & 15.00 & 110.0 & 110.0 & 250.0 & 200.0 & 0.70 & 101.0 & 3.00 \\
\hline $\begin{array}{l}\text { Phenotypic } \\
\text { Variance }\end{array}$ & 1.76 & 10.3 & 9.2 & 324.5 & 140.4 & 0.00 & 73.9 & 0.02 \\
\hline Error Variance & 0.62 & 3.7 & 3.2 & 138.4 & 79.4 & 0.00 & 17.5 & 0.01 \\
\hline $\begin{array}{l}\text { Genotypic } \\
\text { Variance }\end{array}$ & 1.14 & 6.5 & 6.0 & 186.1 & 61.0 & 0.00 & 56.4 & 0.01 \\
\hline Heritability & 0.65 & 0.6 & 0.7 & 0.6 & 0.4 & 0.15 & 0.8 & 0.66 \\
\hline
\end{tabular}

The genetic advance as percent of mean (GA\%) was high for plant height, ear height, plant aspect, ear aspect, cob weight, number of grains per row, stand count at harvest, grain yield, number of diseased cob and cob length (Emmanuel, 2013). Genetic advance as percent of mean was moderate for days to $50 \%$ anthesis, days to $50 \%$ silking and number of cobs per plant. Genetic advance as percent of mean was low for days to $50 \%$ maturity (Badu et al., 2012).

In view of the fact that, high heritability does not always indicate a high genetic gain, heritability should be used together with genetic advance in predicting the ultimate effect for selecting superior varieties. In this study, high heritability and high genetic advance were recorded for plant height number of grains per row, stand count at harvest and cob length which could be considered as essential traits for maize improvement by selection (Bello et al., 2012).

The study showed variation for almost all the traits studied among the tested hybrids, which is an indication of the presence of sufficient variability and can be exploited through selection. The significant difference in grain yield and other agronomic traits among various hybrids were probably due to diverse back ground from which the hybrids where developed. VH132059 and VH11128 were shown higher grain yield compared to others. Consequently, these hybrids can be a preferable choice for further crop improvement. The higher grain yield of the above genotypes could be correlated to the higher number of grain per row and cob weight. Among the tested hybrids VH15471 and VH15884 are early maturing, while VH11153 and VH112944 are late maturing varieties.

\section{Acknowledgement}

The authors are highly acknowledged to CIMMYT, Global maize programme, Hyderabad for providing materials for testing in our station.

\section{References}

Allard RW (1960). Principles of Plant Breeding. John Willy and Sons Inc., USA.

Annapurna D, Khan HA, Mohammad S (1998). Genotypic phenotypic Correlations and path coefficient analysis between seed yield and other associated characters in tall genotypes of maize. Crop Research 16: 205-9.

Assefa T (1998). Survey of maize diseases in western and north- western Ethiopia. In 
the sixth Eastern and Southern Africa Regional Maize Conference, CIMMYT. Addis Ababa, Ethiopia. pp. 121-124.

Badu AB, Fakorede MAB, Menkir A, Sanogo D. Editors (2012). Conduct and management of maize field trials. IITA, Ibadan, Nigeria.59 pp.

Bello OB, Ige SA, Azeez MA, Afolabi MS, Abdulmaliq SY, Mahamood J (2012). Heritability and Genetic Advance for Grain Yield and its Component Characters in Maize (Zea mays L.). IJPR, 2(5): 138-145.

Benti, T, K Mulata, W Olde L, W Olku M, Tulu L (1997). Reflections on the successful achievements of hybrid maize breeding program in Ethiopia. In: Ransom (ed.). Maize Productivity gains through research and technology dissemination. Fifth Eastern and Southern Africa Regional Maize Conference Arusha Tanzania. CIMMYT, Addis Ababa, Ethiopia.

Beyene YA (2005).Phenotypic diversity of morphological and agronomical traits in traditional Ethiopian highland maize accessions. South African J. Plant and Soil. 22:100-105.

Burton GW, De vane EH (1953). Estimating heritability in Tall Fescue (Festuca arundinacea) from replicated clonal material. Agronomy Journal. 45: 481-487.

Daniel T (2014). Evaluation of Improved Maize Genotypes for Grain Yield and Yield Components in Chilga District, North Western Ethiopia. IJSR: 2319-7064.

Gardeah Vah E (2013). Evaluation of maize top cross hybrids for grain yield and associated traits: 82.

FAOSTAT, (2008). Monitoring and Assessment of Greenhouse Gas Emissions and
Mitigation Potential in Agriculture (MAGHG)

GolamMd A, Umakanta SM, Bhagya RB (2014). Genetic variability of yield and its contributing characters on CIMMYT maize in breds under drought stress. Bangladesh J. Agril. Res. 39(3): 419-426.

Iqbal, M., M. Saleem and O. Rashid (2001).Inter-racial heterosis in maize hybrids. Pak. J. Sci. Indus. Res., 44: 239243.

Johnson HW, Robinson HF, Comstock RE (1955). Estimates of genetic and environmental variability in soybeans. Agronomy Journal, 47: 314-318.

Lorenzana RE, Bernardo R (2008). Genetic correlation between corn performance in organic and conventional production systems. Crop Sci. 48: 903-910.

Manivannan NA (1998). Character association and components analysis in maize. Madras Journal of Agriculture 85:293294

Manjunatha B and Niranjana Kumara B (2018), Variability Studies in Advanced Genotypes of Rice (Oryza sativa L.), Trends in Biosciences 10(41), 8707-8708.

Muhammad I (2009). Genetic analysis of maturity and yield attributes in subtropical maize. Department of plant breeding and genetics faculty of crop production sciences agricultural university, Peshawar Pakistan. 112 - 113.

Ram Reddy, Farzana Jabeen, Sudarshan MR, Seshagiri Rao A (2012). Studies on genetic variability, heritability, correlation and path Analysis in maize (Zea mays L.) Over locations. IJABPT, 4: 0976- 4550.

\section{How to cite this article:}

Manjunatha, B., B. Niranjana Kumara and Jagadeesh, G.B. 2018. Performance Evaluation of Maize Hybrids (Zea mays L.). Int.J.Curr.Microbiol.App.Sci. 7(11): 1198-1203. doi: https://doi.org/10.20546/ijcmas.2018.711.139 